\title{
of Hearing Aids
}

\author{
Kevin J. Munro, PhD
}

Changes in the sensory environment modify our sensory experience and may result in experience-related or learning-induced reorganization within the central nervous system. Hearing aids change the sensory environment by stimulating a deprived auditory system; therefore, they may be capable of inducing changes within the central auditory system. Examples of studies that have shown hearing aid induced perceptual and/or physiological changes in the adult human auditory system are discussed. Evidence in the perceptual domain is provided by studies that have investigated (a) speech perception, (b) intensity discrimination, and (c) loudness perception. Evidence in the physiological domain is provided by studies that have investigated acoustic reflex thresholds and event-related potentials. Despite the controversy in the literature concerning the rate, extent, and clinical significance of the acclimatization effect, there is irrefutable evidence that the deprived auditory system of some listeners can be modified with hearing aid experience.

Keywords: reorganization; plasticity; hearing aids; acclimatization; auditory deprivation
I $\mathrm{t}$ is more than a decade since Stuart Gatehouse organized the first Eriksholm Workshop (sponsored by The Oticon Foundation) focusing on the topics of auditory deprivation and auditory acclimatization after the fitting of hearing aids to adults. This workshop was an occasion for analysis, synthesis, and reflection of information and knowledge on these two related topics. The outcome of the workshop was published in a special supplement to Ear \& Hearing, edited by Stuart Gatehouse (1996). Deprivation and acclimatization refer to the concept that the ability to use auditory information may be affected by listening experience; deprivation implies that the absence of experience leads to a decline in ability, whereas acclimatization implies that auditory experience leads to an improvement in auditory ability. The members of the workshop produced formally

From the School of Psychological Sciences, University of Manchester, United Kingdom.

Address correspondence to: Dr. Kevin J. Munro, School of Psychological Sciences, University of Manchester, M13 9PL, U.K.; e-mail: kevin.munro@manchester.ac.uk. agreed definitions for these terms in the workshop report, as follows:

Auditory deprivation effect: the auditory deprivation effect is a systematic decrease (over time) in auditory performance associated with the reduced availability of acoustic cues.

Auditory acclimatization: auditory acclimatization is a systematic change in auditory performance with time linked to a change in the acoustic information available to the listener. It involves an improvement in performance that cannot be attributed purely to task, procedural, or training effects. (Arlinger, Gatehouse, \& Bentler, 1996)

The special supplement contains a series of review articles (along with the workshop report) that provide a link between behavioral measures of auditory function - the traditional domains of audiologists and hearing scientists and the neurophysiological mechanisms that ultimately determine performance. At the time of the Eriksholm Workshop, it was known that neurophysiological changes of the central auditory system (CAS) could be induced by hearing 
impairment, auditory stimulation, and sound conditioning procedures, although there was no direct evidence of hearing aid induced physiological changes in the published literature. However, the insightful decision of the organizer to look beyond the boundaries of a single research field means that the special supplement provides the reader with access to a diverse set of research literature that, even today, is not readily available in any other form.

The purpose of this tutorial article is to bring together the examples of studies that have shown hearing aid induced perceptual and/or physiological changes in the adult human auditory system (see Table 1). It includes studies that were published before the Eriksholm Workshop, newer studies that have been published subsequently, and preliminary data from ongoing studies. The more recent experimental studies have been motivated, at least in part, by the research contained in the special supplement. There is now, for example, tentative evidence of hearing aid induced physiological changes in the adult auditory system. These recent findings are important because not only do they corroborate the behavioral findings using objective test procedures, but they also help us to understand the mechanisms underlying the phenomena of auditory deprivation and auditory acclimatization.

The earliest studies that investigated the improvements in performance following a period of hearing aid use were often motivated by the clinical need to know when is the best time to measure hearing aid benefit (e.g., measure at the time of fitting or after a period of hearing aid use), whereas many of the very recent studies have been motivated by a desire to understand the dynamic nature of the mature auditory system. Taken collectively, studies show irrefutable evidence that the deprived auditory system of some listeners can be modified with the use of hearing aid. This observation is consistent with the growing body of literature, which shows that the mature CAS is malleable and is modified by experience.

This article relies substantially on the work of Stuart Gatehouse and colleagues for several reasons: (a) Because this special issue honors the memory of Stuart Gatehouse, it is appropriate that his body of work on auditory acclimatization is discussed in its entirety, (b) many of the most robust experiments on auditory acclimatization were conducted by Stuart Gatehouse and colleagues, and (c) the tutorial is simplified by focusing on studies reporting only withinsubject comparisons, and this was a feature of the Gatehouse acclimatization studies.
Almost all of the studies discussed in this article used participants who were elderly listeners with a symmetrical hearing impairment but fitted with a monaural hearing aid. These studies were not designed with the intention of advocating monaural fittings (although the evidence base for the additional benefit accrued from a second hearing aid is still surprisingly sparse); rather, they were undertaken in an environment of publicly funded health care (the United Kingdom National Health Service [U.K. NHS]), for which the norm, at that time, was to provide adults with one hearing aid. From the perspective of experimental design, this allows for a within-subject comparison: the ear with no hearing aid acts as a matched control condition. A within-subject design is extremely useful for detecting small but consistent differences between conditions (in this case, comparing ears with and without a hearing aid) in the face of large overall differences between subjects.

The general definition of auditory acclimatization neither makes no assumptions concerning the aspects of auditory performance that may change over time nor does it make any assumption concerning the mechanisms by which the auditory information has been changed; however, it does makes it clear that the improvement in performance is not simply because of the procedural aspects of the experiment unrelated to changes in real-world auditory experience. Acclimatization can be measured by the change in relative performance between the ears as a result of unilateral auditory stimulation: The acclimatization occurring during test sessions and task learning are equal for each ear, but they differ in amount of everyday listening experience.

This tutorial is organized under two headings: Perceptual Evidence of Functional Reorganization After Fitting a Monaural Hearing Aid and Evidence of Physiological Reorganization After Fitting a Monaural Hearing Aid. Evidence in the perceptual domain is provided by studies that have investigated (a) speech perception, (b) intensity discrimination, and (c) loudness perception. Evidence in the physiological domain is provided by studies that have investigated (a) acoustic reflex thresholds and (b) event-related potentials.

Throughout this article, the ear fitted with the hearing aid is referred to as the fitted ear, whereas the ear not normally fitted with the hearing aid is referred to as the not-fitted ear, the latter being considered as the control ear. These terms are used to avoid confusion between the aided and unaided test condition, which could apply to each ear. On the other hand, 


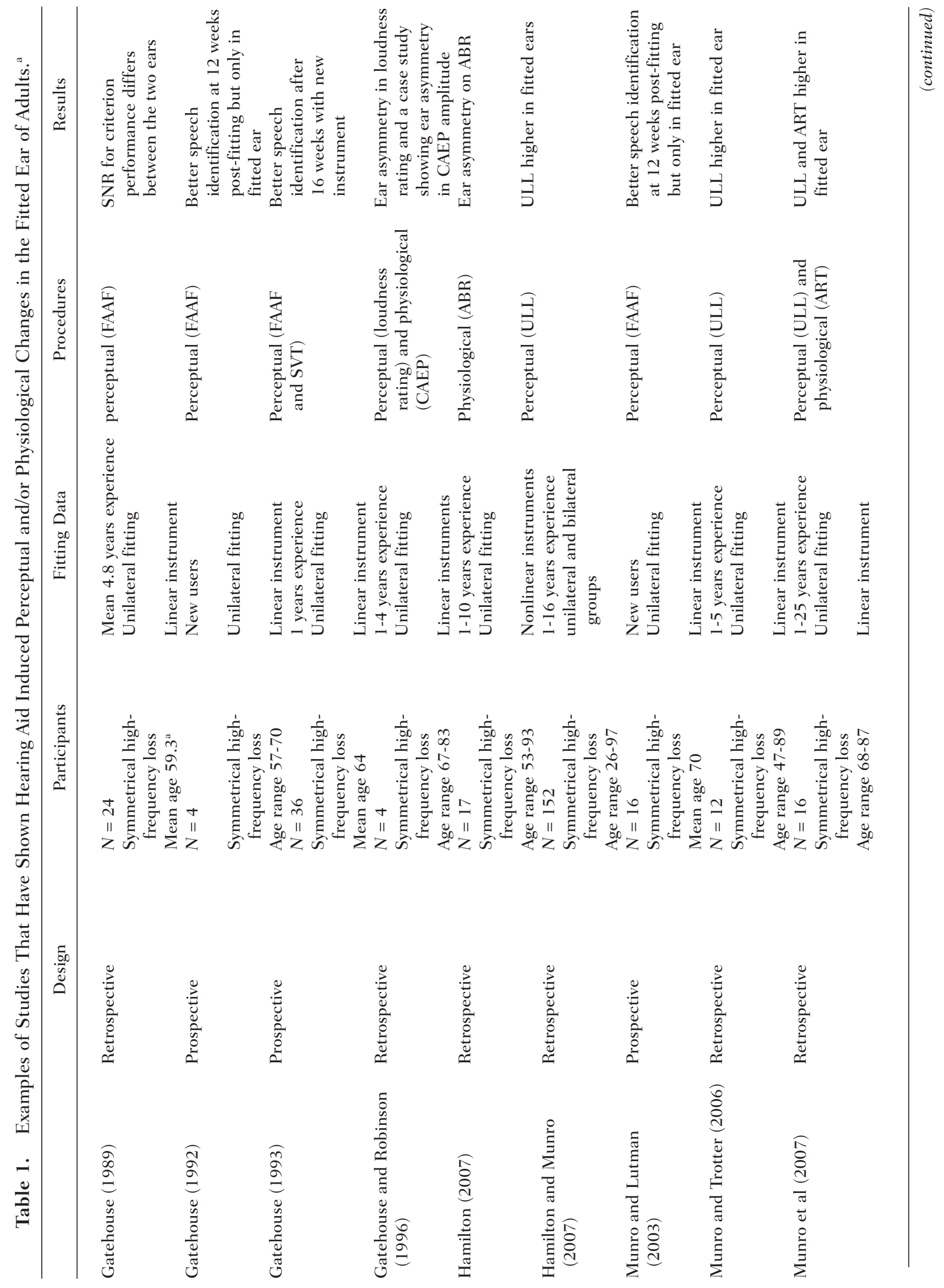




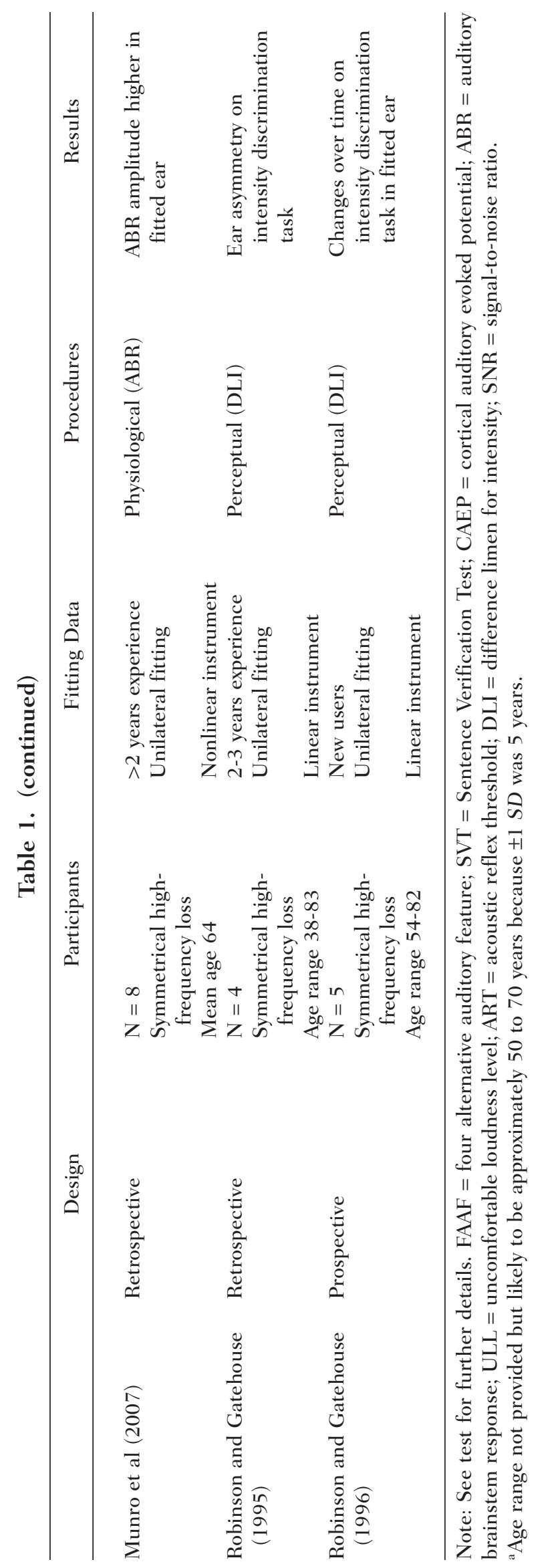


hearing aid benefit refers to the difference in performance between the fitted and not-fitted ear.

\section{Perceptual Evidence From the Monaural Fitting of Hearing Aids}

\section{Speech Perception}

Silman, Gelfand, and Silverman (1984) were the first to report the phenomenon of late-onset auditory deprivation in the not-fitted ear of adults who have a bilateral hearing impairment but use a hearing aid in only one ear. A monosyllabic speech recognition test was administered before fitting the hearing aid and again 4 to 5 years after fitting in two groups of participants who had a mild-to-moderate bilateral sensorineural hearing impairment. One group of participants consisted of 44 men (mean age $=59$ years) who had been fitted monaurally. The second group consisted of 23 men (mean age $=57.9$ years) who had been fitted bilaterally. The test material consisted of Central Institute for the Deaf W-22 phonetically balanced words presented over headphones at $40 \mathrm{~dB}$ re: speech reception threshold (SRT) - defined as the lowest level at which the participant is able to score $50 \%$ correct. Because the SRT was about 40 to $50 \mathrm{~dB} \mathrm{HL}$, the presentation level of speech was approximately 80 to $90 \mathrm{~dB}$ HL. Despite no change in pure tone thresholds, there was a mean decrease of $18.2 \%$ in the speech recognition score (SRS) for the not-fitted ear, but there was no significant decrement in the fitted ear. On the other hand, listeners who had been fitted with bilateral hearing aids showed no asymmetry in speech recognition performance. The stability of the suprathreshold SRS for more than 4- to 5-year period in the fitted ear might be interpreted as an absence of acclimatization, but it should be noted that the test conditions did not simulate the normal hearing aid condition.

Unilateral auditory deprivation has now been shown to occur, for a period of years, in adults and children having a bilateral hearing impairment but with an experience of one hearing aid, and in a number of case studies, recovery has been shown when participants were refitted with 2 hearing aids (Gelfand, 1995; Silverman \& Silman, 1990). However, a largescale prospective study reporting incidence, magnitude, and time course of the deprivation effect are yet to be conducted. For a review on late-onset auditory deprivation, refer to the study by Neuman (1996).
Gatehouse (1989) suggested that the findings of Silman, Gelfand, and Silverman (1984) might be related to the disparity in the accustomed level of sound stimulation of the two ears of listeners using a single hearing aid. An ear that is accustomed in receiving a high level of stimulation (by virtue of use of the hearing aid) will acclimatize to the pattern of cues presented and will be most effective at analyzing high presentation levels. This hypothesis was tested in a group of 24 monaurally fitted adults (mean age = 54.3 years) with a mild-to-moderate bilateral sensorineural hearing impairment. The participants were tested after a mean duration of the use of hearing aid for 4.8 years. They reported that they were wearing their hearing aids, on average, for 8.6 hours per day. The signal-to-noise ratio (SNR) required to obtain the $50 \%$ performance on the four alternative auditory feature (FAAF) test, as a function of speech presentation level, was measured. The FAAF test is a closed-set word discrimination in noise task with no visual cues, and correct identification is strongly dependent on the audibility of high-frequency speech sounds (Foster \& Haggard, 1979, 1987). The results showed the expected improvement in performance for both ears as the presentation level of speech increased from 65 to $90 \mathrm{~dB}$ SPL; criterion performance was obtained at a less favorable SNR at high presentation levels. More importantly, the results show that a more favorable SNR was required in the fitted ear at lower presentation levels than the not-fitted ear (difference of $3.2 \mathrm{~dB}$ ); in contrast, a more favorable SNR was required in the not-fitted ear at high presentation levels compared with the fitted ear (difference of 3.0 $\mathrm{dB}$ ). A difference of $3 \mathrm{~dB}$ is substantial and represents an equivalent of around $20 \%$ difference in score because mean performance changes at a rate of $6 \%$ per decibel change in SNR approximately at the range of $40 \%$ to $80 \%$ (Foster \& Haggard, 1987). The results at the higher presentation levels replicate the findings of Silman et al. (1984) - that is, at high presentation levels, the fitted ear performed more efficiently than the not-fitted ear. The general pattern of findings is shown in Figure 1. The features of note are: (a) Criterion performance was obtained with a less favorable SNR at high presentation level for both ears, (b) criterion performance was obtained with a less favorable SNR in the not-fitted ear at low presentation levels and in the fitted ear at high presentation levels, and (c) the change in SNR with presentation level is larger in the fitted ear. As there were no baseline measures, it is not possible to say whether the 


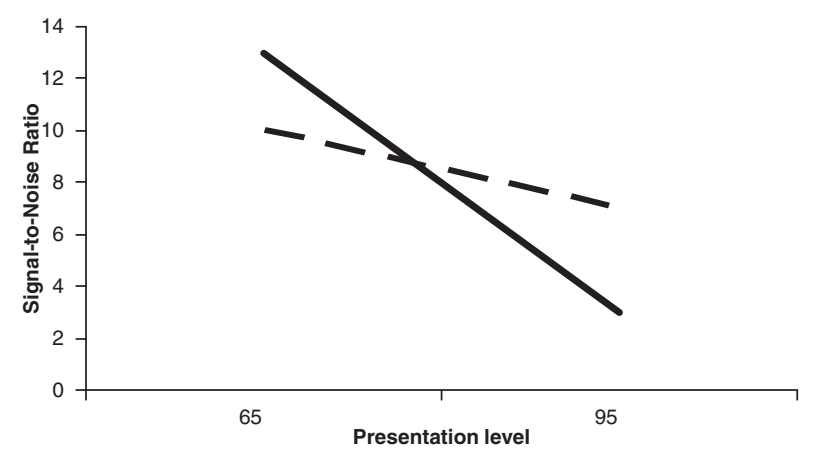

Figure 1. The general pattern of change in SNR for $50 \%$ performance as a function of presentation level. The solid and broken lines correspond to the fitted and not-fitted ear, respectively. Illustration based on data reported by Gatehouse (1989).

asymmetry in SNR is because of the acclimatization of the fitted ear or the result of the (relative) deprivation of the not-fitted ear. Although both ears met criterion performance with a less favorable SNR at high presentation levels, Gatehouse interpreted the findings as evidence that the ear performs most efficiently at a presentation level that is assumed to represent its normal listening level for speech.

The definition of auditory deprivation provided in the Eriksholm Workshop is viewed as being purely negative: Absence of experience results in a decline in performance. The findings of Gatehouse (1989) refer to exposure to low instead of high sound levels rather than an absence of stimulation. Therefore, it is a matter of perspective whether the not-fitted ear is being deprived of high-level stimulation or whether it is being acclimatized to low-level stimulation. It may also be relevant that the deprivation effect appears to be confined to suprathreshold abilities: hearing thresholds and SRTs have not been shown to decline over time. There may be an advantage in the not-fitted ear becoming acclimatized to low-intensity (but audible) sounds and the fitted ear becoming acclimatized to high-intensity sounds, as this may extend the intensity range over which the auditory system is effective (Byrne, 1996). Alternatively, the smaller range of SNR's in the not-fitted ear could be interpreted as a reduced ability of the auditory system to operate as effectively as the fitted ear, and this may be the result of relative deprivation.

Subsequent studies by Gatehouse concentrated on changes in performance over time in the ear with hearing aid experience. The results of an elaborate study by Gatehouse (1992) showed changes in the aided and unaided condition obtained on 10 occasions for a period of 12 weeks commencing from the time of hearing aid fitting. The measurements were limited to a single 80-item run of the FAAF test. Four new hearing aid users (age range 55-70 years) participated in the study. They were typical of first-time hearing aid users in the U.K. with pure tone thresholds around $30 \mathrm{~dB}$ HL at $0.5 \mathrm{kHz}$ and $65 \mathrm{~dB}$ HL at 4 $\mathrm{kHz}$. Each participant was fitted monaurally with a linear instrument. The prescription method was not reported, but examination of the raw data shows that compared with the National Acoustics Laboratory (NAL-R) prescription formula, the real ear insertion gain (REIG) was approximately 10 and $5 \mathrm{~dB}$ higher than the target at 2 and $4 \mathrm{kHz}$, respectively. There was no systematic change in the user-gain setting after 5 weeks post-fitting. The amount of daily use made of the hearing aid was not reported, so it is difficult to know just how familiar the participants were with amplified speech. The participants were tested in the sound field and under a variety of headphone conditions, one of which simulated the electroacoustic characteristics of the hearing aid. Using headphones and a variety of frequency-gain response conditions (e.g., high frequency emphasis versus flat response) reduced the possibility of the participant being motivated to provide a better score with the condition that simulated the hearing aid.

A schematic that illustrates the general pattern of findings reported by Gatehouse is shown in Figure 2. Performance in the fitted and not-fitted ear is shown in the panels on the left and right, respectively. The top panels show aided and unaided performance, and the bottom panels show benefit - that is, the difference between the aided and unaided scores. The aided and unaided performance (and benefit) remained stable in the not-fitted ear. However, in the fitted ear, there was a statistically significant change over time commencing from around 4 to 6 weeks after fitting: there was an increase in the aided score, and a corresponding decrease in the unaided score, and this resulted in an increase in benefit. The initial benefit was about $5 \%$, and this subsequently increased to nearer $15 \%$. The relatively low benefit obtained initially appears to be a characteristic of studies that have reported an acclimatization effect. While the change in aided and unaided performance was discussed in the context of the contribution to the subsequent improvement in benefit, the implications for dependency on the hearing aid were not discussedthat is, the unaided performance deteriorated over time in the fitted ear. This finding can also be observed from the raw data of other studies, such as 

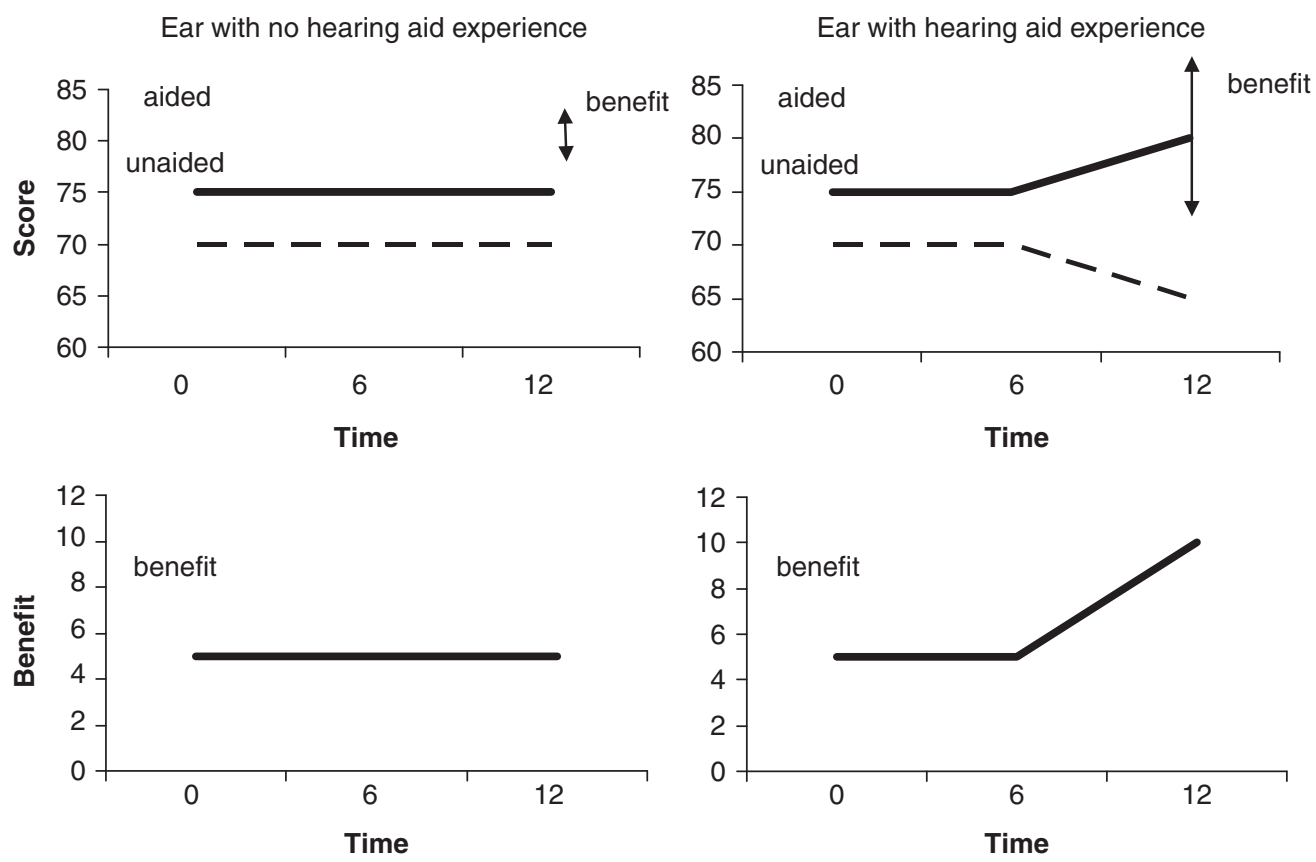

Figure 2. Illustration showing general pattern of changes in speech perception abilities with the use of hearing aid. The top panels show aided and unaided performance (solid and broken lines, respectively). The bottom panels show the benefit, which is the aided performance minus the unaided performance. The panel on the left and right show the not-fitted and fitted ear, respectively. Illustration based on data reported by Gatehouse (1992).

Cox, Alexander, Taylor, and Gray (1996). This decrement in the fitted ear is not the same as the late-onset auditory deprivation that may occur in the not-fitted ear. It is possible to speculate the anecdotal reports that hearing aid users become dependent on their aids, may be due to, at least in part, late-onset auditory deprivation in the not-fitted ear and poorer unaided performance in the fitted ear when the hearing aid was removed.

In 1993, Gatehouse published an article comparing performance with two hearing aids of different frequency responses for a post-fitting period of 16 weeks. The study involved 36 monaurally fitted participants with a mean age of 64 years and mean pure tone thresholds sloping from $31 \mathrm{~dB} \mathrm{HL}$ at 0.5 $\mathrm{kHz}$ to $57 \mathrm{~dB} \mathrm{HL}$ at $4 \mathrm{kHz}$. The participants had been previously fitted with a standard U.K. NHS linear hearing aid for 12 to 15 months, and it was assumed that auditory acclimatization would be essentially complete by this time. This NHS fitting failed to match the NAL-R targets for REIG by 11 , 17 , and $20 \mathrm{~dB}$ at 2,3 , and $4 \mathrm{kHz}$, respectively. The participants were refitted with a new monaural hearing aid that was within $3 \mathrm{~dB}$ of the NAL-R target at $2 \mathrm{kHz}$ and within $5 \mathrm{~dB}$ at 3 and $4 \mathrm{kHz}$. In effect, the study compared differences in high-frequency amplification; a limited high-frequency response was compared with a theoretically more advantageous high-frequency response. It is not clear how the gain of the hearing aids were set on each test session, although it is likely that the U.K. NHS fitting was tested at the user gain recorded on Week 0 , and the new fitting was tested at the fixed target gain setting. There was no difference in the patterns of daily use between the two hearing aids as assessed by simple self-report, although the actual duration of use was not reported. Measurements were carried out at Weeks 0,8 , and 16 for both hearing aids using wordidentification performance on the FAAF test and the Sentence Verification Test (SVT) presented in a background of noise. The SVT is a speech-in-noise test, but in addition to scoring word identification, the response time of the participant to verify that the sentence is silly or sensible is recorded. Therefore, there were a total of three measures: performance on the identification of FAAF test and SVT and the response time on the SVT.

There was no difference in the mean performance on the FAAF test obtained with the two hearing aids when the new instrument was first fitted. 
However, by Week 16, performance with the new hearing aid exceeded the original fitting by $4.4 \%$, and this difference was statistically significant. Similar findings were obtained for both of the SVT measures: with the original hearing aid, criterion performance required a more favorable SNR (mean $+0.7 \mathrm{~dB})$ and a longer reaction time (mean $+312 \mathrm{~ms}$ ).

The acclimatization effect has been reported by others, including Cox and Alexander (1992), Cox et al. (1996), and Horwitz and Turner (1997). In contrast, several studies have failed to show auditory acclimatization (Bentler, Neibuhr, Getta, \& Anderson, 1993; Humes, Halling, \& Coughlin, 1996; Humes, Wilson, Barlow, \& Garner, 2002; Munro \& Lutman, 2000; Saunders \& Cienkowski, 1997; Surr, Cord, \& Walden, 1998; and Taylor, 1993). This has led some researchers to state that the acclimatization effect is nonexistent or so small that it is hard to measure (Turner \& Bentler, 1998). For a review, see the articles by Turner, Humes, Bentler, and Cox (1996) and Palmer, Nelson, and Lindley (1998). The conflicting findings suggest that acclimatization may only be apparent under certain test conditions. There are at least three possible explanations. First, the listening environment of the participants may have been changed little by the use of amplification because of the (a) mild hearing impairment and low hearing aid gain, (b) previous hearing aid experience, or (c) limited use of a hearing aid (Bentler et al., 1993; Taylor, 1993). Second, Robinson and Summerfield (1996) suggest that the negative findings may be because of the specificity of perceptual learning; the test methods used may not be sensitive to changes that had occurred (e.g., bilaterally fit participants tested under monaural listening conditions). Third, findings may only be present on speech perception tests at certain presentation levels. Studies showing acclimatization have tended to show a small initial benefit score (generally less than 5\% to $7 \%$ ), whereas many of the studies that have not showed acclimatization show a much larger initial benefit (greater than 10\%).

Figure 3 illustrates how the difference in benefit scores is related to the presentation level. This was based on hypothetical data, but the general pattern has been reported in many studies, such the acclimatization study by Munro and Lutman (2003) summarized below, and illustrates the influence of presentation level on performance. The filled circles show the aided scores, and the open circles show the unaided scores for speech with a fixed SNR. Performance increases in the unaided condition as

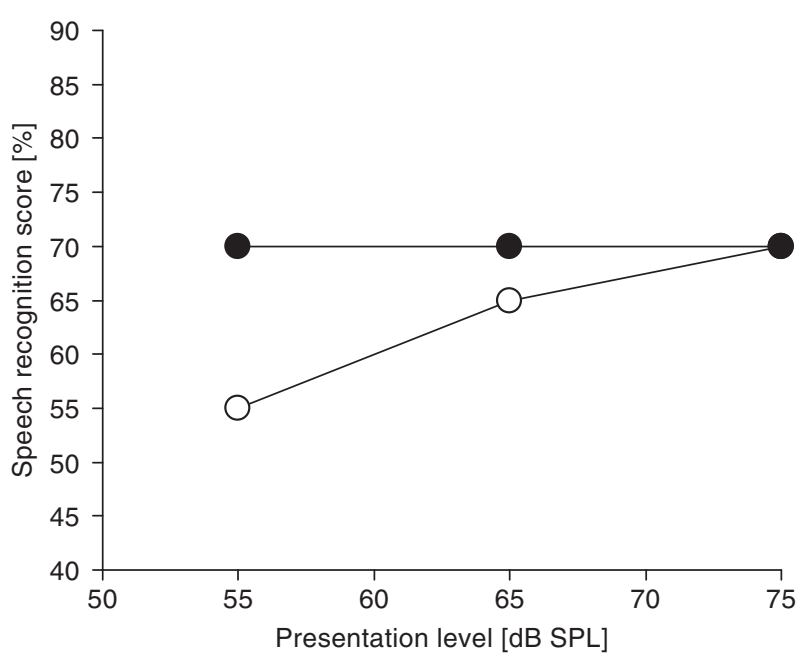

Figure 3. Speech recognition scores and presentation level. The open circles correspond to the unaided condition, and the filled circles correspond to the aided condition.

the presentation level increases. This is because a greater proportion of the speech signal is above threshold of hearing at these relatively high presentation levels. For simplicity, Figure 3 shows a fixed level of performance in the aided condition irrespective of presentation level. This is because audibility is now limited by the background noise, and the fixed SNR means that the same proportion of the speech signal is audible at all presentation levels. Some studies indicate that performance remains constant at high speech presentation levels (e.g., Duquesnoy \& Plomp, 1983), whereas others indicate that the performance is reduced (e.g., Larson, Williams, \& Henderson, 2000; Studebaker, Sherbecoe, McDaniel, \& Gwaltney, 1999). This latter rollover effect is presumably related to increased upward spread of masking, resulting in vowels masking consonants. The studies that have shown an improvement in performance over time have a small initial benefit score. This is consistent with a relatively high presentation level (although it is difficult to make direct comparisons across studies because of differences in calibration procedures). This suggests that the acclimatization is related to the presentation level; it can be measured at relatively high presentation levels but not for relatively low presentation levels. If this is correct, then auditory acclimatization cannot be related to changes in audibility per se because the smallest change in audibility occurs with high presentation levels. 
Munro and Lutman (2003) tested the hypothesis that auditory acclimatization is greatest at relatively high presentation levels. This was obtained by measuring aided and unaided speech recognition in 16 newly aided participants using the FAAF test presented at 55, 62, and $69 \mathrm{~dB}$ SPL (to represent quiet, average, and raised speech, respectively). All participants had a symmetrical, mild-to-moderate, sloping, high-frequency sensorineural impairment and were fitted with a monaural, linear hearing aid set to NAL-RM target values (Byrne \& Dillon, 1986). In reality, the user gain was typically $4 \mathrm{~dB}$ less than the target values at high frequencies. The volume control was disabled for the duration of the study. The number of participants who reported using their hearing aids for more than 8 hours per day was never fewer than 13 (82\%). Four alternative auditory-feature measures were performed at the time of fitting and 6 and 12 weeks post-fitting. After 12 weeks of hearing aid experience, the mean benefit score had increased in the fitted ear by $2.0 \%, 3.2 \%$, and $5.9 \%$ for a presentation level of 55, 62, and $69 \mathrm{~dB}$ SPL, respectively. This change over time was because of an increase in the aided score and a small reduction in the unaided score. The corresponding increase in benefit in the not-fitted ear was less than $1 \%$, irrespective of presentation level. This pattern of results is similar to those reported by Gatehouse (1992) and is illustrated in Figure 2. The results of this study confirm that presentation level is important when measuring acclimatization. The Gatehouse study (1989) also showed a level-dependent effect.

A summary of an experiment that measured the acclimatization effects with linear and nonlinear signal processing was included in an article on outcome measures by Gatehouse (1998). Although many of the details related to the experimental design were not provided in this summary, one observation was that the acclimatization effect differed with presentation level; acclimatization was present at a presentation level of 65 and $75 \mathrm{~dB}$ hearing level (SPL) but not at $55 \mathrm{~dB}$ hearing level (SPL). This finding is consistent with the level-dependent effects reported by Munro and Lutman (2003).

The theoretical and empirical analyses reported in this section add to our understanding of the conditions under which auditory acclimatization can be measured: Amplifying speech to a new and less familiar listening level may be required for measurement of acclimatization. Thus, the commonly held view that acclimatization is because of the participant learning to make use of newly audible speech sounds may not be correct.

\section{Intensity Discrimination}

Robinson and Gatehouse (1995) investigated the difference limen for intensity (DLI) in 4 hearingimpaired participants. The participants (age range $=$ 54 to 82 years) had a mean pure tone threshold of 24 $\mathrm{dB} H \mathrm{HL}$ at $0.25 \mathrm{kHz}$ and $58 \mathrm{~dB}$ HL at $3 \mathrm{kHz}$. Each participant had been fitted with a linear monaural hearing aid for a mean of 2 years and 7 months. The REIG was $0 \mathrm{~dB}$ at $0.25 \mathrm{kHz}$ and $19 \mathrm{~dB}$ at $3 \mathrm{kHz}$. The control group consisted of 5 normal-hearing individuals in the age range of 18 to 35 years. The DLI was measured with tone complexes of 0.25 and $3 \mathrm{kHz}$ at 65,80 , and 95 dB SPL, respectively. Difference limens were measured using the gated pedestal method with an adaptive, three-alternative, and forced-choice procedure for a criterion performance of $71 \%$ correct.

The results showed that the fitted ear behaved differently from the not-fitted ear. At $3 \mathrm{kHz}$, DLI was poorer at low presentation levels but better at high presentation levels in the fitted ear. The simplest explanation for this finding is that intensity discrimination changed as a result of exposure to amplified sound. The level-dependent effects parallel the findings of Gatehouse (1989) for speech identification in noise.

Because it is possible that the asymmetry at 3 $\mathrm{kHz}$ was present before hearing aid fitting, Robinson and Gatehouse (1996) carried out a prospective study of intensity discrimination in 5 individuals (age range $=38$ to 83 years) who were fitted with a monaural, linear, peak-clipping hearing aid. The participants had a bilateral sensorineural hearing impairment with a mean pure tone threshold (in the fitted ear) of $23 \mathrm{~dB}$ HL at $0.25 \mathrm{kHz}$ and $69 \mathrm{~dB} \mathrm{HL}$ at $3 \mathrm{kHz}$. The hearing aids were fitted according to the NAL-R target for REIG. There was a mean of 1 $\mathrm{dB}$ gain at $0.25 \mathrm{kHz}$ (target $0 \mathrm{~dB}$ ) and $19 \mathrm{~dB}$ at $3 \mathrm{kHz}$ (target $19 \mathrm{~dB}$ ). The stimuli, equipment, and procedures were the same as those used in the previous study. Measurements were carried out at 0 to 4,6 to 12 , and 15 to 18 weeks post-fitting. The results show that immediately after fitting, there was no difference between the two ears for either stimulus. At $0.25 \mathrm{kHz}$, there was no difference between the ears when the study terminated at 18 weeks post-fitting. However, at $3 \mathrm{kHz}$, there was a progressive influence of hearing aid experience with the difference limen being significantly smaller in the fitted ear at high presentation levels when the study terminated at 18 weeks post-fitting. This study shows that the fitted ear becomes progressively better able to discriminate 

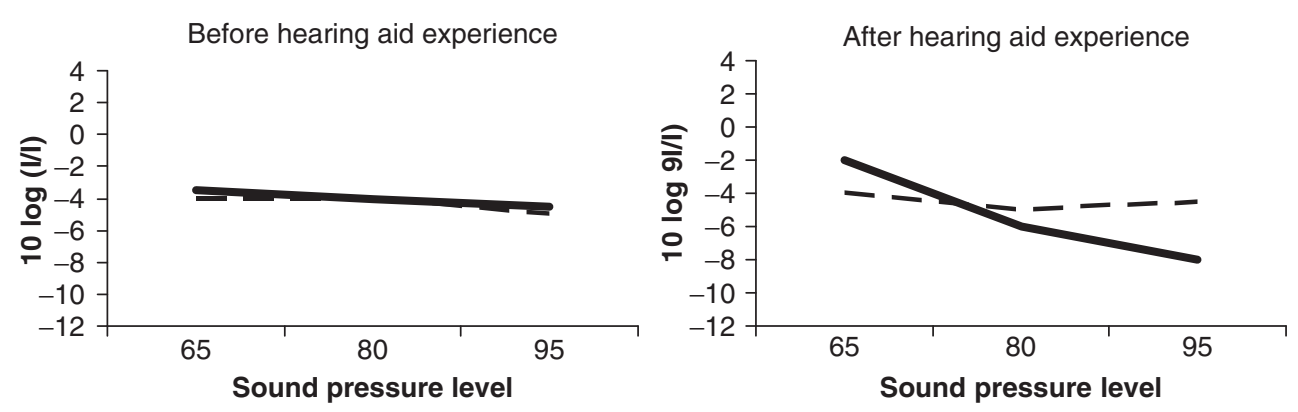

Figure 4. Illustration showing general pattern of changes in intensity discrimination threshold as a function of sound presentation level at a frequency that receives amplification. The left and right panels illustrate the findings before and after fitting of hearing aid, respectively. The solid and dashed lines refer to the fitted and not-fitted ear, respectively. Illustration based on observations reported by Robinson and Gatehouse (1995, 1996).

intensity at the highest sound pressure level for frequencies that are normally amplified by the hearing aid. Use of hearing aid for 15 to 18 weeks was required before this was observed. There was little or no change over time at lower sound pressure levels, at frequencies not amplified by the hearing aid, or in the not-fitted ear. A schematic summary of the general pattern of findings is provided in Figure 4. The panel on the left shows the similarity of the two ears of the unilaterally aided participants before fitting. The panel on the right shows the pattern after the use of unilateral hearing aid. The results are displayed as Weber fractions: a low value on the ordinate corresponds to better intensity discrimination.

\section{Loudness Perception}

Gatehouse and Robinson (1996) investigated loudness perception in 4 listeners who had a symmetrical sensorineural hearing impairment and were experienced users of a linear monaural hearing aid. The participants were between 67 and 83 years of age, and pure tone thresholds were approximately $30 \mathrm{~dB}$ HL at $0.5 \mathrm{kHz}$ and $65 \mathrm{~dB}$ HL at $2 \mathrm{kHz}$. The REIG was around $3 \mathrm{~dB}$ at $0.5 \mathrm{kHz}$ and $25 \mathrm{~dB}$ at 2 $\mathrm{kHz}$. Loudness perception was measured at intervals between fixed anchor points of $+12 \mathrm{~dB}$ above hearing threshold and uncomfortable loudness level (ULL). There was no difference in loudness ratings between the two ears at $0.5 \mathrm{kHz}$, where the hearing aid made negligible change to the acoustic environment. However, there was a statistically significant difference between the two ears at $2 \mathrm{kHz}$, whereby the hearing aid provided material gain-essentially, the functions were less steep in the fitted ear.
Munro and Trotter (2006) investigated ULL's in a group of adults with a fitting of unilateral hearing aid. They hypothesized that ULL's would be symmetrical pre-fitting and asymmetrical post-fitting (with increased tolerance in the fitted ear). There were 12 participants who were the first-time hearing aid users ranging in age from 47 to 89 years (mean $=77$ years). They presented with a symmetrical, high-frequency sensorineural hearing impairment with mean hearing thresholds of around $40 \mathrm{~dB} H \mathrm{HL}$ at $0.5 \mathrm{kHz}$ and $65 \mathrm{~dB}$ HL at $4 \mathrm{kHz}$. Participants were fitted with a single linear hearing aid using NAL gain/frequency response prescription targets, and maximum power output was adjusted if there was any report of loudness discomfort; however, the user gain and maximum output of the hearing aids were not recorded. The ULL's were measured immediately before fitting the hearing aid and 12 to 60 months (mean $=32$ months) after fitting. Pure tones were presented to each ear separately, commencing at $60 \mathrm{~dB}$ HL (duration and interstimulus interval of approximately $1 \mathrm{~s}$ ) and increased in increments of $5 \mathrm{~dB}$ until ULL was reached. The reported daily use of the hearing aid at the time of the post-fitting measures was 1 to 16 hours (median $=5$ hours). Mean ULL's were similar in both ears before fitting. After unilateral hearing aid experience, there was a statistically significant asymmetry with higher values (i.e., greater tolerance of loudness) in the ear with hearing aid experience, especially at the high frequencies (mean difference of $8 \mathrm{~dB}$ at 2 and $4 \mathrm{kHz}$ ). Munro, Walker, and Purdy (2007) have since replicated these findings.

The ear-specific nature of the changes is consistent with the specific nature of perceptual learning frequently reported in the literature (Robinson \& 
Summerfield, 1996). For example, studies in which human participants were trained on frequency discrimination (Demany, 1985; Irvine, Martin, Klimkeit, \& Smith, 2000), temporal discrimination (Wright, Buonomano, Mahnvcke, \& Merzenich, 1997), and sound localization (Wright \& Fitzgerald, 2001) tasks have all shown some degree of specificity to the training stimulus. The specific nature of perceptual learning has been reported in other sensory systems; training on visual discrimination often does not transfer to the opposite eye, to different spatial orientations, or to different tasks involving the same stimuli (Fahle \& Morgan, 1996; Shui \& Pashler, 1992).

All of the foregoing studies have assumed that the asymmetry in perceptual abilities is a feature of a dynamic auditory system. However, because most acclimatization studies have used unilateral (and linear) fittings, these changes may only be present when an asymmetry is introduced into the auditory system. Hamilton and Munro (2007) measured ULL's in three groups of participants: unilateral users, bilateral users, and a control group with no previous hearing aid experience. The number of participants in the unilateral and bilateral group was 50 and 48, respectively. The control group consisted of 54 participants who were about to be fitted with their first hearing aid. All participants were elderly listeners with a symmetrical high-frequency hearing impairment. The hearing aid users had a minimum 2 years of experience. The ULL's were measured using the same procedure as the earlier study by Munro and Trotter (2006). There was a statistically significant difference in ULL between the fitted and not-fitted ears, and the mean ULL was around $4 \mathrm{~dB}$ higher in the fitted ears. The ULL in the bilateral users was higher than the control group, and there was an asymmetry in the ULL in the unilateral hearing aid users. Therefore, ULL's are higher in fitted ears irrespective of unilateral or bilateral fitting. The author could not be certain that all participants were making regular use of their hearing aids, so it is likely that $4 \mathrm{~dB}$ was an underestimate of the potential maximum effect. These findings are consistent with the contention that a change in perceptual abilities after fitting of hearing aid is a characteristic of a dynamic auditory system and is not restricted solely to unilateral hearing aid experience. Philibert, Collet, Vesson, and Veuillet $(2002,2005)$ studied loudness perception in listeners provided with bilateral hearing aids. In the first study, loudness perception was compared in experienced hearing aid users and in a group of ageand hearing-matched controls. The experienced hearing aid users rated sounds as less loud than the controls, and this difference was statistically significant at $2 \mathrm{kHz}$. In the second study, loudness perception was measured repeatedly for the first 24 weeks of hearing aid use. Moderate- and high-level sounds were rated as less loud over time, and this was statistically significant for the high frequencies; however, there was no control group so it is not possible to rule out changes because of the practice from repeated test exposure.

\section{Physiological Evidence From Monaural Fitting of Hearing Aids}

In relatively recent times, it has become clear that the sensory areas in the brain of adult humans retain a significant degree of plasticity (Buonomano \& Merzenich, 1998; Syka, 2002). Changes in the sensory environment, as a result of deprivation or stimulation, modify our sensory experience and may result in experience-related or learning-induced reorganization within the central nervous system. Although the earliest evidence was provided from studies investigating the visual and somatosensory system, a growing number of electrophysiological and imaging studies have reported physiological changes in the adult human auditory system. These studies have investigated the effects of intensive training on the normal auditory system (Kraus et al., 1995; Menning, Roberts, \& Pantev, 2000), the effects of hearing impairment on a previously normal auditory system (Dietrich, Nieschalk, Stoll, Rajan, \& Pantev, 2001; Ponton et al., 2001), and the effect of electrical stimulation on a deprived auditory system (Purdy, Kelly, \& Thorne, 2001). Refer to the article by Neuman (2005) for a review of CAS plasticity and aural rehabilitation of adults.

Hearing aids change the sensory environment by stimulating a deprived auditory system. Therefore, hearing aids may change the acoustical environment sufficiently to induce changes in the auditory system (either directly or by reversing injury-induced reorganization following hearing impairment). Emerging evidence is provided in recent studies, which are discussed in this section.

\section{Acoustic Reflex Thresholds}

Although there is a growing body of evidence to support perceptual changes after fitting unilateral hearing aid in some elderly listeners, few studies 
have investigated physiological changes in this population. Munro, Walker, et al. (2007) investigated both perceptual and physiological asymmetry in unilateral hearing aid users for the first time. They investigated ear asymmetry in ULL and the acoustic reflex threshold (ART) in adult humans following long-term use of a monaural hearing aid. There is a known relationship between the ULL and the level at which there is a reflex contraction of the muscles in the middle ear (Olsen, 1999). Although theories for the existence of the middle-ear reflex are unresolved, if the ART is elevated along with the ULL, then this would provide direct evidence of adaptive plasticity in the adult auditory system.

Uncomfortable loudness level and ART's (ipsi and contralateral) were measured in 16 elderly listeners $(9$ men and 7 women; age range $=68$ to 87 years) who had a symmetrical age-related hearing impairment and were experienced users of a monaural hearing aid. The median duration of use was 3 years (range = 1 to 25 years), and the median self-reported daily use was 10 hours (range $=4$ to 16 hours). All participants were using a nonlinear hearing aid that provided most amplification at the high frequencies when the hearing impairment was greatest. Mean REIG was around $20 \mathrm{~dB}$. Uncomfortable loudness levels were obtained by presenting pure tones to each ear separately at 60 dB HL (duration and interstimulus interval of approximately $1 \mathrm{~s}$ ) and increasing in increments of $5 \mathrm{~dB}$ until the listeners indicated that the threshold of discomfort had been reached. Acoustic reflex thresholds were obtained by presenting pure tones at $70 \mathrm{~dB} \mathrm{HL}$ and increasing in increments of $5 \mathrm{~dB}$. The presence of an acoustic reflex was established by confirming an increase in reflex growth when the eliciting signal was increased from the estimated ART to ART $+5 \mathrm{~dB}$. The level was then reduced by $10 \mathrm{~dB}$, and the ascending sequence was repeated to verify the lowest level required to elicit a decrease in middle-ear compliance of at least $0.2 \mathrm{~mL}$. The results showed that the mean ULL's and reflex thresholds were higher in the fitted ear by +2 to $+9 \mathrm{~dB}$, depending on frequency. The asymmetry was greatest at the high frequencies, and this was almost certainly underestimated at $4 \mathrm{kHz}$ because it was not always possible to measure a reflex in the fitted ear. Elevation of the ART occurred in the ear with hearing aid experience irrespective of the ear of stimulation.

Because the pathways for the acoustic reflex lie in the auditory brainstem (Borg, 1973), the findings of Munro, Walker, et al. (2007) suggest that hearing aids can induce physiological changes in the adult auditory brainstem. This finding is somewhat unexpected because the general form of auditory reorganization in adults is an expanded representation for lesion-edge frequencies at the level of the auditory cortex (Rajan \& Irvine, 1998). On the other hand, there is growing evidence for experience-related molecular and cellular changes at the brainstem level in the adult auditory system and somatosensory system (Illing, 2001; Illing \& Reisch, 2006; Xu \& Wall, 1999).

It is possible that there is a cascade of changes ascending from the peripheral to the CAS. Alternatively, there may be top-down influences via efferent pathways. The ascending limb of the acoustic reflex pathway includes the primary auditory neurons and the cochlear nucleus neurons. The mode of transfer of this information to the motor neurons involves an intermediate neuron at the level of the medial superior olivary complex. There are tonotopically organized efferent connections to the superior olivary complex from higher centers, including the inferior colliculus (Borg, 1973). This means that the inferior colliculus is capable of exerting frequency-specific effects on the superior olivary complex. The elevated reflex thresholds measured in the ear with hearing aid experience, irrespective of the ear of stimulation, is important as this shows that adaptive changes to the efferent pathways may have influenced the ascending limb of the reflex pathway on the fitted side. Khalfa, Bougeard, and Morand (2001) examined the influence of the efferent system on peripheral auditory function after cortical lesions in humans with intractable epilepsy. They noted that the olivocochlear system was less functional after surgery, especially on the side contralateral to the lesion. In other patients, the olivocochlear system became more effective on the side ipsilateral to the lesion. Thus, the efferent system appears to mirror the afferent pathways, and there is evidence of peripheral amplitude modulation by the auditory cortex in humans.

\section{Event-Related Potentials}

Gatehouse (1996) measured the amplitude of the N1-P2 complex in a single adult with a moderate, symmetrical high-frequency hearing impairment who received high-frequency amplification from a monaural hearing aid. The stimuli consisted of low- and high-frequency tones over a range of presentation levels. There was no difference between ears for the low-frequency stimulus when the hearing aid provided no material amplification. However, the high-frequency stimulus resulted in a larger amplitude 
response in the fitted ear at high presentation levels but a smaller amplitude response at low presentation levels. Likewise, this pattern of high-frequency asymmetry was present on perceptual tasks. The subject showed a steeper loudness function in the fitted ear at high presentation levels. On the other hand, the fitted ear was better able to discriminate intensity at high presentation levels but not at low presentation levels. This was a single case study with no baseline measures before the hearing aid was fitted; arguably, it may be the first direct evidence of perceptual and neurophysiological asymmetry in a long-term user of a monaural hearing aid.

To further explore the possibility of hearing-aidinduced physiological changes at the level of the brainstem, Munro, Pisareva, Parker, and Purdy (2007) investigated ear asymmetry in the auditory brainstem response $(\mathrm{ABR})$ in adult humans after long-term use of a monaural hearing aid. It was hypothesized that the latency may be shorter and/or amplitude may be greater in the fitted ear because exposure-induced plasticity results in better neural synchronization and/or greater neural activation. The ABR was recorded from two groups of participants. One group of 9 participants ( 7 men, 2 women) with a mean age of 69 years $(S D \pm 9.0)$ had yet to be fitted with a hearing aid. A second group of participants (4 men, 4 women) with a mean age of 64 years $(S D$ $\pm 7.6)$ were long-term users of a nonlinear monaural hearing aid (minimum 2 years of experience and selfreported daily use of greater than 5 hours). The mean hearing thresholds for both groups were close to 20 $\mathrm{dB} H \mathrm{HL}$ at $0.5 \mathrm{kHz}$ and $60 \mathrm{~dB} \mathrm{HL}$ at $4 \mathrm{kHz}$. The REIG was around 16 to $18 \mathrm{~dB}$ at the higher frequencies, where the hearing-impairment was greatest $(0.5 \mathrm{kHz}$, $0 \mathrm{~dB} \pm 7 \mathrm{~dB} ; 1 \mathrm{kHz}, 9 \pm 6 \mathrm{~dB} ; 2 \mathrm{kHz}, 16 \pm 4 \mathrm{~dB}$; $4 \mathrm{kHz}, 18 \pm 7 \mathrm{~dB})$. Stimuli consisted of $0.1 \mathrm{~ms}$ rarefaction rectangular clicks presented monaurally at 70,80 , and $90 \mathrm{~dB}$ nHL. The peak-to-peak amplitude and absolute latency of the dominant waves were recorded. There was no statistically significant difference between the right and left ears of either group, or there was no statistically significant interaction between ear and presentation level. The data from the experienced monaural hearing aid users were then categorized according to the hearing aid ear (fitted or not-fitted ear). The mean latency data were similar for the fitted and not-fitted ear. However, the mean peak-to-peak amplitude data for wave $\mathrm{V}$ to $\mathrm{SN}_{10}$ were higher in the fitted ear at 70 and $80 \mathrm{~dB}$ nHL. The amplitude reaches an asymptote in the fitted ear around $80 \mathrm{~dB} \mathrm{nHL}$, and as a result, the difference between the two ears disappears at $90 \mathrm{~dB}$ nHL. The simplest explanation for this finding is that physiological changes occurred as a result of experience to amplification, although a prospective study has yet to be reported.

Recordings from humans and animals suggest that the neural generator for wave $\mathrm{V}$ is the lateral lemniscus and for the $\mathrm{SN}_{10}$ is the inferior colliculus (IC), both contralateral to the stimulated ear (Moller \& Jannetta, 1982; Moller, Jannetta, \& Jho, 1994). There is evidence of plasticity occurring at the level of the IC in adult animals. For example, Willot (2006) has shown reorganization of the IC and the auditory cortex in fast-ageing mice that have an accelerated highfrequency hearing impairment. Almost all ascending pathways synapse in the IC; hence, this represents a site of convergence of information that has been processed in parallel in the different brainstem nuclei. The convergence of activity from lower levels in the pathway, or the complex neural circuitry of the IC, may explain why reorganization is apparent at this level of the auditory pathway. The acoustic reflex study by Munro, Walker, et al. (2007) mentioned earlier showed an asymmetry in the acoustic reflex pathway. The SOC probably contributes to wave IV of the $\mathrm{ABR}$, but this wave is not always present in humans and was not reliably present in the participants used in the ABR study. In a study of similar design, Hamilton (2007) reported that the mean amplitude showed a nonsignificant trend of higher amplitude in the fitted ear. There was a statistically significant difference in mean latency with earlier values in the fitted ear. When participants identified as poor users were removed from the analysis, the asymmetry became larger. A previous study investigated the ABR in bilateral hearing aid users (Philibert et al., 2005). No amplitude changes were reported although the latency of wave $V$ reduced by a mean of $0.2 \mathrm{~ms}$ on the right side, compared with the time of fitting, but remained unchanged on the left side. This is a difficult finding to explain given that hearing was symmetrical before and after the fitting of bilateral hearing aid.

The processes by which reorganization occur after a change in sensory input is not well understood (and it is not clear whether these are the same for deprivation and stimulation). Eggermont (2006) has suggested that a hearing-loss deprivation may result in a cascade of events commencing with a change in excitatory-inhibitory inputs (because of unmasking) followed by a change in synaptic strength (as a result of use-dependent changes), and then structural 


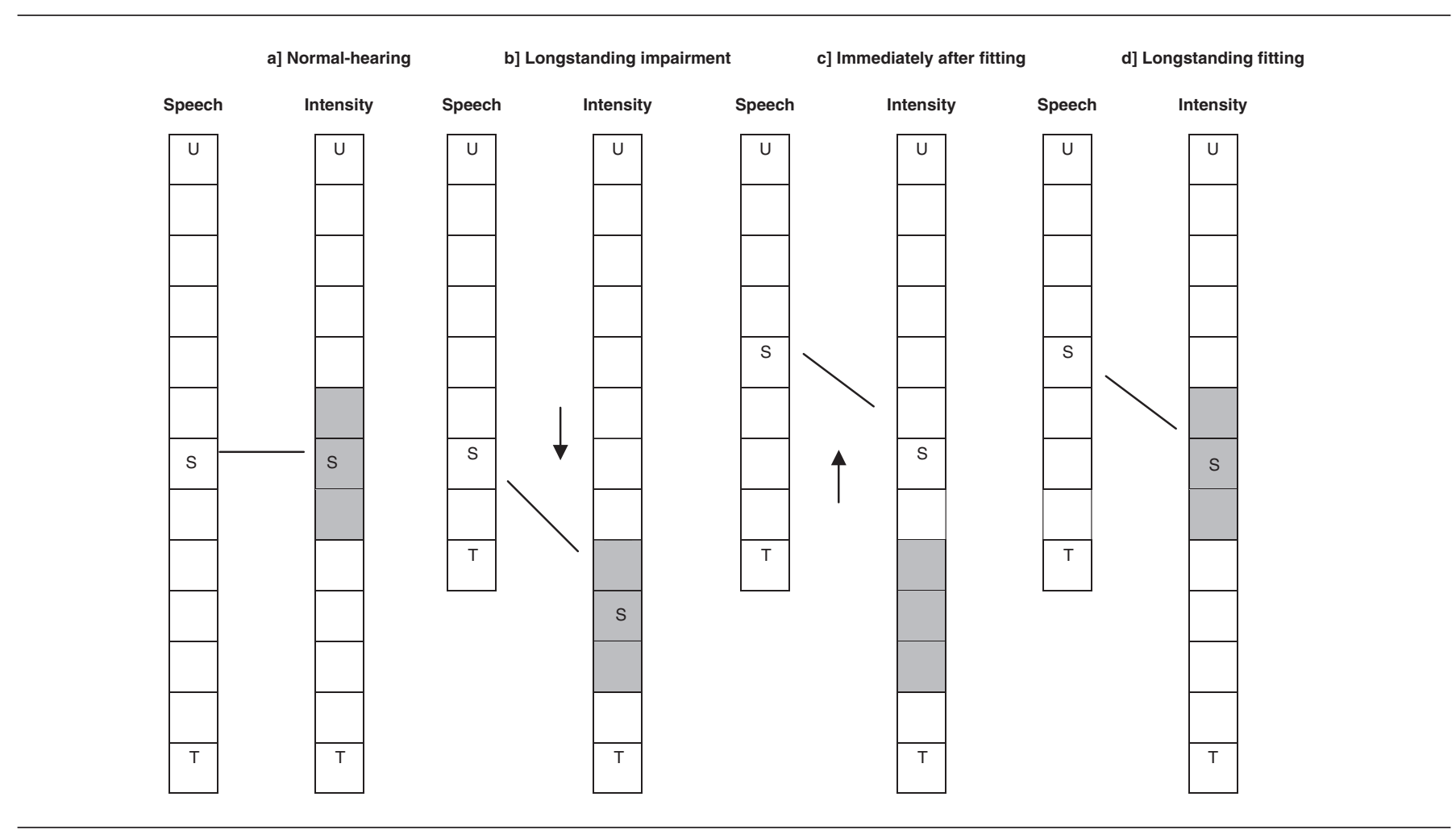

Figure 5. Conceptual framework showing the mapping of the external speech signal and its neural representation along the intensity domain. The symbols T, U, and S represent the sound pressure level at threshold, uncomfortable loudness level, and conversational speech, respectively. The normal relationship is shown in a, b: after a longstanding hearing impairment, the neural representation acclimatizes. c: Immediately after fitting, there is a mismatch between the concentration of neural resources in the intensity domain and the location of speech within the CNS. d: After regular use of a hearing aid, the neural representation reacclimatizes so that the concentration of neural resources within the CNS occurs for speech.

changes with the formation of new synapses and sprouting of axons.

Although it is generally accepted that there is a link between brain physiology and behavior, it is not clear how reorganization within the CAS equates to perceptual changes. A conceptual framework that may explain why changes in performance can occur following regular use of a hearing aid is shown in Figure 5. The normal relationship is shown in Figure $5 \mathrm{~A}$ with conversational speech ( $\mathrm{S}$; left column) being mapped to the middle of the neural representation of the signal in the intensity domain ( $\mathrm{S}$; right column). This mapping is represented by the horizontal line connecting the two columns. The purpose of the shaded area is to show that neural resources are concentrated around the position of conversational speech within the CAS. In a listener with a longstanding hearing impairment, the level of conversational speech is unchanged, although the speech signal is now attenuated by the peripheral auditory system. As a result, speech is located in a different position within the CAS (as shown by the downward facing arrow in Figure 5B). However, reorganization has occurred within the CAS so that resources have become concentrated at the lower end of the neural representation to reflect the position of conversational speech within the auditory range of the listener. Immediately after provision of amplification, the input level of conversational speech increases, and this alters the location of speech within the intensity domain (as shown by the upward facing arrow in Figure 5C). A hearing aid will confer immediate benefit through the provision of new audible information. However, there is a mismatch between the concentration of neural resources located at the lower end of the intensity domain and the external speech signal. After a period of hearing aid experience, there is reorganization of the neural map to accommodate the shift in the intensity domain; neural resources become concentrated at a higher position in the intensity domain where speech is located (as shown in Figure 5D). It is possible that subsequent improvements in performance are the result of this reorganization. 
The dependence of acclimatization on presentation level can be rationalized as follows. Consider a listener who experiences speech in everyday life in the range of 55 to $75 \mathrm{~dB}$ SPL before fitting and 75 to $95 \mathrm{~dB}$ SPL after fitting (i.e., the hearing aid provides $20 \mathrm{~dB}$ linear gain). For simplicity, the shape of the gain and frequency response curve is not considered here. If speech test materials are presented at $55 \mathrm{~dB}$, they are amplified to $75 \mathrm{~dB}$; hence, there is little difference compared with that experienced before amplification, that is, amplified soft speech falls within the upper boundary of neural representation. However, if material is presented at $70 \mathrm{~dB}$ and amplified to $90 \mathrm{~dB}$, this reaches a level that is unfamiliar. The organism must adapt and reorganize to discriminate and use the speech cues that are now coded into an unfamiliar part of the intensity domain. In the foregoing example, reorganization would be required to discriminate speech presented at $70 \mathrm{~dB}$ but not at $55 \mathrm{~dB}$. Dean, Harper, and McAlpine (2005) have shown that neurons in the auditory midbrain are mutable and improve their coding of sound levels by rapidly adjusting their sensitivity to the local auditory environment. As the fitted ear becomes more experienced at listening to higher sound levels, the auditory neurons may become more effective at coding high-level stimuli.

If this explanation is correct, then the neurophysiological changes are a feature of a dynamic auditory system; these changes could potentially occur in listeners with normal hearing who are regularly exposed to a high sound pressure level.

Formby, Sherlock, and Gold (2003) showed changes in loudness tolerance in normal-hearing listeners who wore earplugs or low-level noise generators for 2 weeks. After wearing earplugs, the ULL reduced by around $8 \mathrm{~dB}$; after using noise generators, the level at which sounds became uncomfortably loud increased by about $8 \mathrm{~dB}$. Likewise, although acclimatization effects are commonly reported as a high-frequency phenomenon, it is hypothesized that these changes will occur at any frequency that is modified by amplification.

The clinical implications of CAS reorganization with respect to the use of hearing aid are unclear (Willott, 1996). It is probably misleading to assume that all reorganization is beneficial. One of the most dramatic examples of CNS plasticity is the reorganization that occurs in the sensory map within the cortex following limb amputation and phantom limb pain (Yang, Gallen, Schwartz, \& Bllom, 1994). Tinnitus can be considered as analogous to phantom limb pain
(Salvi, Wang, \& Ding, 2000; Weisz, Wienbruch, Dohrmann, \& Elbert, 2005). These examples of perceptual consequences of reorganization are regarded as undesirable. On the other hand, reorganization may form the basis for desensitizing sound therapies used in treating hyperacusis and related sound-tolerance problems (Formby et al., 2003).

\section{Conclusion}

A growing number of studies have reported perceptual changes in the adult human, and there is now emerging evidence of changes in the physiological domain.

These recent findings are important because not only do they corroborate the behavioral findings using objective test procedures but also help us to understand the mechanism underlying the phenomena of auditory deprivation and auditory acclimatization. There is irrefutable evidence that the deprived auditory system of some listeners can be modified by hearing aid experience. The use of hearing aids can provide a useful route to explore the nature and extent of reorganization in adults. Prospective studies are now required that investigate the dynamic properties of the adult central auditory system, the perceptual consequences of any reorganization, and, ultimately, to determine whether these changes are of benefit to the patient. We continue to benefit from the prescience of Stuart Gatehouse and, in particular, the multidisciplinary nature of the first Eriksholm Workshop that he organized.

\section{References}

Arlinger, S., Gatehouse, S., \& Bentler, R. A. (1996). Report of the Eriksholm Workshop on auditory deprivation and acclimatization. Ear \& Hearing, 17, 87S-98S.

Bentler, R. A., Neibuhr, D. P., Getta, J. P., \& Anderson, C. V. (1993). Longitudinal study of hearing aid effectiveness I: Objective measures. Journal of Speech, Language, and Hearing Research, 36, 808-819.

Borg, E. (1973). On the neural organisation of the acoustic middle ear reflex. Brain Research, 49, 101-123.

Buonomano, D. V., \& Merzenich, M. M. (1998). Cortical plasticity: From synapses to maps. Annual Review of Neuroscience, 21, 149-186.

Byrne, D. (1996). Implications of acclimatization for hearing aid fitting practices and research. Ear \& Hearing, 17, 25S-26S.

Byrne, D., \& Dillon, H. (1986). The National Acoustics Laboratories (NAL) new procedure for selecting the 
gain and frequency response of a hearing aid. Ear $\varepsilon$ Hearing, 7, 257-265.

Cox, R. M., \& Alexander, G. C. (1992). Maturation of hearing aid benefit: Objective and subjective measurements. Ear E Hearing, 13, 1311-1341.

Cox, R. M., Alexander, G. C., Taylor, I. M., \& Gray G. A. (1996). Benefit acclimatization in elderly hearing aid users. Journal of the American Academy of Audiology, 7, 428-441.

Dean, I., Harper, N. S., \& McAlpine, D. (2005). Neural population coding of sound level adapts to stimulus statistics. Nature Neuroscience, 8, 1684-1689.

Demany, L. (1985). Perceptual learning in frequency discrimination. Journal of the Acoustical Society of America, 78, $1118-1120$.

Dietrich, V., Nieschalk, M., Stoll, W., Rajan, R., \& Pantev, C. (2001). Cortical reorganization in patients with high frequency cochlear hearing loss. Hearing Research, 158, 95-101.

Duquesnoy, A. J., \& Plomp, R. (1983). The effect of a hearing aid on the speech reception threshold of hearingimpaired listeners in quiet and in noise. Journal of the Acoustical Society of America, 73, 2166-2173.

Eggermont, J. (2006). A time-line of auditory cortical reorganization after noise-induced hearing loss. In S. Lomber \& J. Eggermont (Eds.), Programming the central cortex (pp. 143-158). Oxford, UK: Oxford University Press.

Fahle, M., \& Morgan, M. (1996). No transfer of perceptual learning between stimuli in the same retinal position. Current Biology, 6, 292-297.

Formby, C., Sherlock, L. P., \& Gold, S. L. (2003). Adaptive plasticity of loudness induced by chronic attenuation and enhancement of the acoustic background. Journal of the Acoustical Society of America, 114, 56-58.

Foster, J. R., \& Haggard, M. P. (1979). FAAF. An effective analytical test of speech perception. Proceedings of the Institute of Acoustics, 182, 9-12.

Foster, J. R., \& Haggard, M. P. (1987). The four alternative auditory feature test (FAAF): Linguistic and psychometric properties of the material with normative data in noise. British Journal of Audiology, 21, 165-174.

Gatehouse S. (1989). Apparent auditory deprivation effects of late onset: The role of presentation level. Journal of the Acoustical Society of America, 86, 2103-2106.

Gatehouse S. (1992). The time course and magnitude of perceptual acclimatization to frequency responses: Evidence from monaural fitting of hearing aids. Journal of the Acoustical Society of America, 92, 1258-1268.

Gatehouse S. (1993). Role of perceptual acclimatization in the selection of frequency responses for hearing aids. Journal of the American Academy of Audiology, 4, 296-306.

Gatehouse, S. (Ed.). (1996). Proceedings of the 1st Eriksholm Consensus Conference on Auditory Deprivation and Acclimatization. Ear \& Hearing, 17(Suppl.), S1-S98.

Gatehouse, S. (1998). Speech tests as measures of outcome. Scandinavian Audiology, 27, 54-60.
Gatehouse, S., \& Robinson, K. (1996). Acclimatization to monaural hearing aid fitting-effects on loudness functions and preliminary evidence for parallel electrophysiological and behavioural effects. In B. Kollmeier (Ed.), Psychoacoustics, speech and hearing aids (pp. 319-330). Singapore: World Scientific.

Gelfand, S. A. (1995). Long-term recovery and no recovery from the auditory deprivation effect with binaural amplification: Six cases. Journal of the American Academy of Audiology, 6, 141-149.

Hamilton, A. M. (2007). Perceptual and physiological changes in adults who are experienced users of hearing aids. Unpublished master's dissertation, University of Manchester, Manchester, U.K.

Hamilton, A. M., \& Munro, K. J. (2007, November 21-23). The influence of hearing aid experience on uncomfortable loudness levels: Evidence of plasticity? Poster presented at The Annual Conference of the British Academy of Audiology, Telford, U.K.

Horwitz, A. R., \& Turner, C. W. (1997). The time course of hearing aid benefit. Ear \& Hearing, 18, 1-11.

Humes, L. E., Halling, D., \& Coughlin, M. (1996). Reliability and stability of various hearing-aid outcome measures in a group of elderly hearing-aid wearers. Journal of Speech, Language, and Hearing Research, 39, 923-935.

Humes, L. E., Wilson, D. L., Barlow, N. N., \& Garner, C. (2002). Changes in hearing-aid benefit following one, two or three years of hearing aid use by the elderly. Journal of Speech, Language, and Hearing Research, 45, 772-782.

Illing, R. B. (2001). Activity-dependent plasticity in the adult auditory brainstem. Audiology and Neurotology, 6, 319-345.

Illing, R. B., \& Reisch A. (2006). Specific plasticity responses to unilaterally decreased or increased hearing intensity in the adult cochlear nucleus and beyond. Hearing Research, 216-217, 189-197.

Irvine, D. R. F., Martin, R. L., Klimkeit, E., \& Smith, R. (2000). Specificity of perceptual learning in a frequency discrimination task. Journal of the Acoustical Society of America, 108, 2964-2968.

Khalfa, S., Bougeard, R., \& Morand, N. (2001). Evidence of peripheral auditory activity modulation by the auditory cortex in humans. Neuroscience, 104, 347-358.

Kraus, N., McGee, T. J., Carrell, T. D., King, C., Tremblay, K., \& Nicol, T. (1995). Central auditory system plasticity associated with speech discrimination training. Journal of Cognitive Neuroscience, 7, 25-32.

Larson, V. D., Williams, D. W., \& Henderson, W. G. (2000). Efficacy of three commonly used hearing aid circuits. Journal of the American Medical Association, 11, 1806-1813.

Menning, H., Roberts, L. E., \& Pantev, C. (2000). Plastic changes in the auditory cortex induced by intensive frequency discrimination training. Neuroreport, 11, 817-822.

Moller, A. R., \& Jannetta, P. J. (1982). Evoked potentials from the inferior colliculus in man. Electroencephalography and Clinical Neurophysiology, 53, 612-620. 
Moller, A. R., Jannetta, P. J., \& Jho, H. D. (1994). Click-evoked responses from the cochlear nucleus: A study in humans. Electroencephalography and Clinical Neurophysiology, 92, 215-224.

Munro, K. J., \& Lutman, M. (2000, September). Auditory acclimatization to amplified speech. Poster presented at International Hearing Aid Conference (IHCON), Lake Tahoe, NV.

Munro, K. J., \& Lutman M. (2003). The effect of speech presentation level on measurement of auditory acclimatization to amplified speech. Journal of the Acoustical Society of America, 114, 484-495.

Munro, K. J., Pisareva, N. P., Parker, D. J., \& Purdy, S. C. (2007). Asymmetry in the auditory brainstem response following experience of monaural amplification. Neuroreport, 18, 1871-1874.

Munro, K. J., \& Trotter, J. H. (2006). Preliminary evidence of asymmetry in uncomfortable loudness levels after unilateral hearing aid experience: Evidence of functional plasticity in the adult auditory system. International Journal of Audiology, 45, 684-688.

Munro, K. J., Walker, A. J., \& Purdy, S. C. (2007). Evidence for adaptive plasticity in elderly monaural hearing aid users. Neuroreport, 18, 1237-1240.

Neuman, A. C. (1996). Late-onset auditory deprivation: a review of past research and an assessment of future research needs. Ear \& Hearing, 17, 3S-13S.

Neuman, A. C. (2005). Central auditory system plasticity and aural rehabilitation of adults. Journal of Rehabilitation Research and Development, 42, 169-186.

Olsen, S. O. (1999). The relationship between the uncomfortable loudness level and the acoustic reflex threshold for pure tones in normally-hearing and impaired listeners-a meta-analysis. Audiology, 38, 61-68.

Palmer, C. V., Nelson, C. T., \& Lindley, G. A. (1998). The functionally and physiologically plastic adult auditory system. Journal of the Acoustical Society of America, 103, 1705-1721.

Philibert, B., Collet, L., Vesson, J. F., \& Veuillet, E. (2002). Intensity-related performances are modified by longterm hearing aid use: A functional plasticity? Hearing Research, 165, 142-151.

Philibert, B., Collet, L., Vesson, J. F., \& Veuillet, E. (2005). The auditory acclimatization effect in sensorineural hearing-impaired listeners: Evidence for functional plasticity. Hearing Research, 205, 131-142.

Ponton, C. W., Vasama, J. P., Tremblay, K., Khosla, D., Kwong, B., \& Don, M. (2001). Plasticity in the adult human central auditory system: Evidence from lateonset profound unilateral deafness. Hearing Research, 154, 32-44.

Purdy, S. C., Kelly, A. S., \& Thorne, P. R. (2001). Auditory evoked potentials as measures of plasticity in humans. American Annals of the Deaf, 6, 211-215.

Rajan, R., \& Irvine, D. R. F. (1998). Absence of plasticity of the frequency map in dorsal cochlear nucleus of adult cats after unilateral partial cochlear lesion. Journal of Comparative Neurology, 399, 35-46.

Robinson, K., \& Gatehouse, S. (1995). Changes in intensity discrimination following monaural long-term use of a hearing aid. Journal of the Acoustical Society of America, 97, 1183-1190.

Robinson, K., \& Gatehouse, S. (1996). The time course of effects on intensity discrimination following monaural fitting of hearing aids. Journal of the Acoustical Society of America, 99, 1255-1258.

Robinson, K., \& Summerfield, A. Q. (1996). Adult auditory learning and training. Ear \& Hearing, 17, 51S-65S.

Salvi, R. J., Wang, J., \& Ding, D. (2000). Auditory plasticity and hyperactivity following cochlear damage. Hearing Research, 147, 261-274.

Saunders, G. H., \& Cienkowski, K. M. (1997). Acclimatization to hearing aids. Ear \& Hearing, 18, 129-139.

Silman, S., Gelfand, S. A., \& Silverman, C. A. (1984). Lateonset auditory deprivation: Effects of monaural versus binaural hearing aids. Journal of the Acoustical Society of America, 76, 1357-1361.

Silverman, C. A., \& Silman, S. (1990). Apparent auditory deprivation from monaural amplification and recovery with binaural amplification: Two case studies. Journal of the American Academy of Audiology, 1, 175-180.

Studebaker, G. A., Sherbecoe, R. L., McDaniel, D. M., \& Gwaltney C. A. (1999). Monosyllabic word recognition at higher-than-normal speech and noise levels. Journal of the Acoustical Society of America, 105, 2431-2444.

Shui, L. P., \& Pashler, H. (1992). Improvements in line orientation discrimination in retinally local but dependent on cognitive set. Perception E Psychophysics, 52, 582-588.

Surr, R. K., Cord, M. T., \& Walden, B. E. (1998). Long-term versus short-term hearing aid benefit. Journal of the American Academy of Audiology, 9, 165-171.

Syka, J. (2002). Plastic changes in the central auditory system after hearing loss, restoration of function, and during learning. Physiological Review, 82, 601-636.

Taylor, K. S. (1993). Self-perceived and audiometric evaluations of hearing aid benefit in the elderly. Ear \& Hearing, 14, 390-394.

Turner, C. W., \& Bentler, R. A. (1998). Does hearing aid benefit increase over time? Letter to editor. Journal of the Acoustical Society of America, 104, 3673-3674.

Turner, C. W., Humes, L. E., Bentler, R. A., \& Cox, R. M. (1996). A review of past research on changes in hearing aid benefit over time. Ear \& Hearing, 17, 14S-28S.

Weisz, N., Wienbruch, C., Dohrmann, K., \& Elbert, T. (2005). Neuromagnetic indicators of auditory cortical reorganization of tinnitus. Brain, 128, 2722-2731.

Willott, J. F. (1996). Physiological plasticity in the auditory system and its possible relevance to hearing aid use, deprivation effects, and acclimatization. Ear \& Hearing, $17,66 \mathrm{~S}-77 \mathrm{~S}$.

Willott, J. F. (2006). Central auditory plasticity in mouse models of progressive sensorineural hearing loss. In S. Lomber 
\& J. Eggermont (Eds.), Programming the central cortex (pp. 181-192). Oxford, UK: Oxford University Press.

Wright, B. A., Buonomano, D. V., Mahnvcke, H. W., \& Merzenich, M. M. (1997). Learning and generalisation of auditory temporal-interval discrimination in humans. Journal of Neuroscience, 17, 3956-3963.

Wright, B. A., \& Fitzgerald, M. B. (2001). Different patterns of human discrimination learning for two interaural cues to sound-source localisation. Proceedings of the National Academy of Sciences, 98, 12307-12312.

Xu, J., \& Wall, J. T. (1999). Evidence for brainstem and suprabrainstem contributions to rapid cortical plasticity in adult monkeys. Journal of Neuroscience, 19, 7578-7590.

Yang, T. T., Gallen, C., Schwartz, B., Bllom, F. E., \& Ramachandran, V. S. (1994). Sensory maps in the human brain. Nature, 368, 592-593. 